Esta obra está sob o direito de Licença Creative Commons Atribuição 4.0 Internacional.

\title{
ADOECIMENTO E TRANSTORNOS MENTAIS DOS PROFESSORES
}

\author{
Betijane Soares de Barros ${ }^{1}$ \\ Luciana de Omena Gusmão ${ }^{2}$ \\ Rubiana de Omena Gusmão Moreno da Rocha ${ }^{3}$ \\ Cleidejane Soares de Barros ${ }^{4}$ \\ Fernanda Santos Azevedo ${ }^{5}$
}

\section{RESUMO}

O adoecimento e os transtornos mentais dos professores são temas de grande relevância científica, devido ao grande potencial patogênico inerente a profissão docente e ao crescente número de casos de afastamentos desses profissionais por crises de pânico, depressão e transtornos de ansiedade. Os fatores prováveis para o adoecimento são, a deficiência nas formações iniciais e continuada, a ausência do vínculo estável dos professores com os locais de trabalho, salários defasados e a inexistência de políticas públicas para a Educação. O presente trabalho avaliou produções científicas publicadas entre 2015 e 2020, nas bibliotecas BVS, PubMed e ScienceDirect. Os descritores utilizados nas buscas estavam devidamente cadastrados nos bancos de terminologias DeCS e MeSH. O período de coleta dos dados correu no mês de novembro de 2020. Como critérios de inclusão, buscou-se contemplar apenas os artigos científicos publicados nos últimos cinco anos, enquanto os critérios de exclusão, foram considerados apenas os artigos dentro da temática abordada. Espera-se que, com novos estudos sobre a temática se tenha um novo olhar direcionado a promoção da prevenção do adoecimento e os transtornos mentais dos professores, assim como, fomente ampla discussão da distorção da escola como local de adoecimento e da profissão docente caracterizada como de risco, sobretudo, para o adoecimento mental.

PALAVRAS-CHAVE: Saúde Mental. Adoecimento. Transtornos. Professores.

\footnotetext{
${ }^{1}$ marciamg@live.com

2 martaluciadir@gmail.com

3 rubianaomena@hotmail.com

4 dr.csbarros@hotmail.com

5 nanda_azevedoo@hotmail.com
} 


\section{INTRODUÇÃO}

O propósito deste artigo é o de refletir sobre um problema crucial que é vivenciado com veemência no campo da Saúde Mental, que é o adoecimento dos docentes por transtornos mentais (MACHADO e LIMONGI, 2019). A questão central tratada aqui é se existe adoecimento e transtornos mentais decorrentes de condições adversas do professor?

Este é sem dúvida o problema mais espinhoso a ser resolvido no nosso campo de estudos. Não se trata apenas da dificuldade de diálogo com outras áreas do conhecimento, mas sim de um dilema criado no interior de nossas atividades e que não parece vislumbrar uma solução a curto prazo (MACHADO, et al. 2019).

O adoecimento dos professores tornou-se uma questão decisiva nos seus

\section{METODOLOGIA}

O presente trabalho é uma revisão bibliográfica, do tipo sistemática integrativa, que seguiu as seguintes etapas: definição do tema; seleção da pergunta norteadora e escolha da estratégia de busca; descritores e bases de dados mais eficazes no levantamento das publicações; escolha dos critérios de inclusão e exclusão; identificação dos estudos pré-selecionados e selecionados por meio da leitura dos trabalhos, afetando a vida de muitas pessoas hoje acometidas de graves transtornos mentais e que sofrem por não saber a quem recorrer e como fazer valer os seus direitos (MOREIRA e RODRIGUES, 2018).

Além disso, enquanto não se avançar na solução desse dilema, estar-se-á também retardando a adoção de medidas preventivas nos ambientes de trabalho e deixando de cumprir o papel primordial dos profissionais da educação. Acredita-se que se conseguir avançar nessa direção, isto é, de demonstrar de forma efetiva que existem transtornos mentais e, ao mesmo tempo, aprofundar o conhecimento sobre as verdadeiras causas desses transtornos e, consequentemente, avançando na elaboração de medidas preventivas (MOSCHEN PORT e AMAZARRAY, 2019).

agentes indexadores das publicações, como resumos, palavras-chave e títulos, bem como a organização dos estudos préselecionados e a identificação dos estudos selecionados; categorização dos estudos selecionados, com a elaboração e o uso da matriz de síntese, além da análise das informações; a formação de uma biblioteca individual e a avaliação crítica dos estudos selecionados; análise, interpretação e discussão dos resultados e a apresentação da 
revisão em formato de artigo, o qual contempla as propostas para estudos futuros.

No Quadro 1 estão apresentados processo metodológico, tais como, descritores, bibliotecas, strings de busca, entre outros.

detalhes sobre a pesquisa, assim como, seu

Quadro 1 - Detalhamento das etapas da Revisão Sistemática Integrativa.

\begin{tabular}{|c|c|c|c|c|}
\hline ETAPA & $\begin{array}{l}\text { TÓPICOS DE CADA } \\
\text { ETAPA }\end{array}$ & \multicolumn{3}{|c|}{ DETALHAMENTO DE CADA TÓPICO } \\
\hline \multirow[t]{16}{*}{$\mathbf{1}^{\mathbf{a}}$} & Tema & \multicolumn{3}{|c|}{ Do adoecimento aos transtornos mentais dos professores } \\
\hline & Pergunta norteadora & \multicolumn{3}{|c|}{$\begin{array}{l}\text { Existem adoecimento e transtornos mentais decorrentes de } \\
\text { condições adversas do professor? }\end{array}$} \\
\hline & Objetivo geral & \multicolumn{3}{|c|}{$\begin{array}{l}\text { Avaliar o adoecimento e os transtornos mentais decorrentes } \\
\text { das condições adversas de trabalho dos professores. }\end{array}$} \\
\hline & Estratégias de busca & \multicolumn{3}{|c|}{$\begin{array}{l}\text { 1. Cruzamento de descritores por meio do operador booleano } \\
\text { AND; } \\
\text { 2. Uso de aspas nos politermos (descritor com mais de um } \\
\text { termo) para que a varredura de artigos científicos } \\
\text { contemplasse o termo exato; } \\
\text { 3. Uso de descritores estruturados (codificação) no DECS ou } \\
\text { MESH; } \\
\text { 4. Uso de metadados (filtros). }\end{array}$} \\
\hline & \multirow{3}{*}{$\begin{array}{l}\text { Bancos de } \\
\text { terminologias }\end{array}$} & Banco & & Link \\
\hline & & DeSC & http://d & br/ \\
\hline & & $\mathrm{MeSH}$ & https://v & cbi.nlm.nih.gov/mesh \\
\hline & \multirow[t]{4}{*}{$\begin{array}{l}\text { Descritores livres e } \\
\text { estruturados }\end{array}$} & Descritor & $\begin{array}{r}\text { DeSC } \\
\text { (Registı }\end{array}$ & $\begin{array}{l}\text { MeSH (Identificador } \\
\text { Único) }\end{array}$ \\
\hline & & ADOECIMENTO & - & - \\
\hline & & $\begin{array}{l}\text { TRANSTORNOS } \\
\text { MENTAIS }\end{array}$ & 8771 & D001523 \\
\hline & & PROFESSORES & 5278 & D005178 \\
\hline & String de busca & \multicolumn{3}{|c|}{ Adoecimento AND “transtornos mentais" } \\
\hline & \multirow{4}{*}{ Site } & \multirow{4}{*}{$\begin{array}{l}\text { BVS } \\
\text { ScienceDirect } \\
\text { PubMed }\end{array}$} & & Link \\
\hline & & & & /brasil.bvs.br/ \\
\hline & & & https://ww & ncedirect.com/ \\
\hline & & & https://pub & icbi.nlm.nih.gov/ \\
\hline \multirow[t]{3}{*}{$2^{\mathbf{a}}$} & $\begin{array}{l}\text { Período de coleta dos } \\
\text { dados }\end{array}$ & \multicolumn{3}{|c|}{ Novembro de 2020.} \\
\hline & Critérios de inclusão & \multicolumn{3}{|c|}{$\begin{array}{l}\text { 1. Texto (artigos científicos e free). } \\
\text { 2. Publicação (2015-2020). }\end{array}$} \\
\hline & Critérios de exclusão & \multicolumn{3}{|c|}{$\begin{array}{l}\text { 1. Artigos que não contemplam a temática "Adoecimento e } \\
\text { Transtornos Mentais". }\end{array}$} \\
\hline $3^{\mathbf{a}}$ & \multicolumn{3}{|c|}{$\begin{array}{l}\text { Número de trabalhos selecionados para revisão } \\
\text { sistemática a partir da leitura dos agentes indexadores } \\
\text { das publicações (tema, descrição, ementa). }\end{array}$} & 16 \\
\hline $4^{a}$ & \multicolumn{3}{|c|}{$\begin{array}{l}\text { Categorias obtidas com a análise dos documentos } \\
\text { investigados online gratuitos e de livre acesso }\end{array}$} & 3 \\
\hline
\end{tabular}


Fonte: elaborada pelos autores.

\section{RESULTADOS}

Como resultado das buscas realizadas nas bibliotecas listadas no Quadro 1, com a string também supracitadas, obteve-se os quantitativos de artigos científicos descritos no Quadro 2. O total de artigos obtidos nas três bibliotecas consultadas foi de 186, contudo, após a aplicação do filtro e seleção dos artigos que estavam mais relacionados com a temática central do presente trabalho, restaram 16.

Quadro 2 - Corresponde ao total de documentos disponíveis na BVS, PubMed e ScienceDirect obtidos por string de busca.

\begin{tabular}{|c|c|c|c|c|}
\hline String de busca & Bases de dados & $\begin{array}{c}\text { Total de } \\
\text { publicações } \\
\text { sem o filtro }\end{array}$ & $\begin{array}{c}\text { Publicações } \\
\text { disponíveis } \\
\text { após aplicar os } \\
\text { filtros }\end{array}$ & $\begin{array}{c}\text { Publicações } \\
\text { aproveitadas na } \\
\text { Revisão Sistemática }\end{array}$ \\
\hline $\begin{array}{c}\text { Adoecimento } \\
\text { AND "transtornos } \\
\text { mentais" }\end{array}$ & BVS & 181 & 69 & 13 \\
\cline { 2 - 5 } & ScienceDirect & 4 & 2 & 2 \\
\cline { 2 - 5 } $\begin{array}{c}\text { Illness AND } \\
\text { "mental } \\
\text { disorders" }\end{array}$ & PubMed & 1 & 1 & $\mathbf{1 6}$ \\
\cline { 2 - 5 } & TOTAL & $\mathbf{1 8 6}$ & $\mathbf{7 2}$ & \\
\hline
\end{tabular}

Fonte: elaborada pelos autores.

Os 16 artigos selecionados para análise foram baixados das bibliotecas e serviram como base para a confecção das categorias de discussão apresentadas abaixo. O Quadro 3 armazena informações principais sobre os 16 artigos selecionados para análise. Autoria, tema, ano de publicação e as conclusões dos artigos encontram-se nesse Quadro.

Quadro 3 - Descrição dos documentos (artigos) de acordo com os critérios de inclusão.

\begin{tabular}{|c|c|c|c|c|}
\hline $\mathbf{N}^{\mathbf{o}}$ & AUTOR (A) & TEMA & ANO & CONCLUSÃO \\
\hline 1 & $\begin{array}{l}\text { Daniele Alcalá Pompeo } \\
\text { Arélica de Carvalho } \\
\text { Aline Morgado Olive } \\
\text { Maria da Graça Girade } \\
\text { Souza } \\
\text { Sueli Aparecida Frari Galera }\end{array}$ & $\begin{array}{l}\text { Estratégias de } \\
\text { enfrentamento de } \\
\text { familiares de } \\
\text { pacientes com } \\
\text { transtornos mentais }\end{array}$ & 2016 & $\begin{array}{l}\text { Apesar do sofrimento causado } \\
\text { pelo impacto do adoecimento do } \\
\text { seu ente querido, os familiares } \\
\text { utilizam mais estratégias } \\
\text { funcionais, permitindo-lhes } \\
\text { enfrentar as adversidades de } \\
\text { forma mais ajustada. }\end{array}$ \\
\hline 2 & $\begin{array}{l}\text { Bianca Eastwood Gruginskia } \\
\text { Leila Amaral Gontijoa } \\
\text { Eugenio Merinoa }\end{array}$ & $\begin{array}{c}\text { Frequency of } \\
\text { Application of } \\
\text { Mental Workload } \\
\text { Measuring }\end{array}$ & 2015 & $\begin{array}{l}\text { However, the practice of } \\
\text { ergonomic analysis of work } \\
\text { comprising the measurement of } \\
\text { mental workload is rarely seen in } \\
\text { recent national publications. }\end{array}$ \\
\hline
\end{tabular}




\begin{tabular}{|c|c|c|c|c|}
\hline & & $\begin{array}{l}\text { Instruments in Recent } \\
\text { Publications in Brazil }\end{array}$ & & \\
\hline 3 & $\begin{array}{l}\text { Gabriela Oliveira Andradea } \\
\text { Rosa Amélia Andrade } \\
\text { Dantas }\end{array}$ & $\begin{array}{l}\text { Transtornos mentais } \\
\text { e do comportamento } \\
\text { relacionados ao } \\
\text { trabalho em médicos } \\
\text { anestesiologistas }\end{array}$ & 2015 & $\begin{array}{l}\text { A organização do trabalho, } \\
\text { quando não adequada, é um } \\
\text { importante fator de risco } \\
\text { ocupacional para a vida e a saúde } \\
\text { mental dos trabalhadores, } \\
\text { principalmente, dos profissionais } \\
\text { voltados para o cuidado de } \\
\text { pessoas. O foco presente são os } \\
\text { médicos anestesiologistas, } \\
\text { constantemente expostos a } \\
\text { fatores estressantes } \\
\text { ansiogênicos. }\end{array}$ \\
\hline 4 & $\begin{array}{l}\text { Hellany Karolliny Pinho } \\
\text { Ribeiroa } \\
\text { José Diego Marques Santosa } \\
\text { Monaliza de Goes e Silvaa } \\
\text { Flávia Daniele de Alencar } \\
\text { Medeiroa } \\
\text { Márcia Astrês Fernandesa }\end{array}$ & $\begin{array}{c}\text { Transtornos de } \\
\text { ansiedade como } \\
\text { causa de } \\
\text { afastamentos laborais }\end{array}$ & 2018 & $\begin{array}{l}\text { Conhecer o perfil de adoecimento } \\
\text { do trabalhador contribui para } \\
\text { identificar os fatores de risco para } \\
\text { TMC e auxilia na proposição de } \\
\text { estratégias de intervenção } \\
\text { direcionadas a reduzir o } \\
\text { afastamento laboral. }\end{array}$ \\
\hline 5 & $\begin{array}{l}\text { Luciana Cristina Machado } \\
\text { Jean Ezequiel Limongi }\end{array}$ & $\begin{array}{l}\text { Prevalência e fatores } \\
\text { relacionados a } \\
\text { transtornos mentais } \\
\text { comuns entre } \\
\text { professores da rede } \\
\text { municipal de ensino, } \\
\text { Uberlândia, Minas } \\
\text { Gerais, Brasil }\end{array}$ & 2019 & $\begin{array}{l}\text { Os resultados apontam que a } \\
\text { saúde mental do professor carece } \\
\text { de cuidados e comprometimento } \\
\text { nas ações, visto que a saúde } \\
\text { desses profissionais afeta } \\
\text { diretamente os ciclos de ensino- } \\
\text { aprendizagem. A redução do } \\
\text { absenteísmo, presenteísmo, } \\
\text { rotatividade, aposentadorias } \\
\text { precoces e licenças médicas } \\
\text { diminuem os custos para o Estado } \\
\text { e trazem benefícios que se } \\
\text { estendem para toda a sociedade. }\end{array}$ \\
\hline 6 & $\begin{array}{l}\text { Renata Moschen Portz } \\
\text { Mayte Raya Amazarray }\end{array}$ & $\begin{array}{l}\text { Transtornos mentais } \\
\text { comuns e fatores } \\
\text { associados em } \\
\text { trabalhadores } \\
\text { bancários do Rio } \\
\text { Grande do Sul, Brasil }\end{array}$ & 2019 & $\begin{array}{l}\text { Os dados encontrados indicam } \\
\text { elevado sofrimento psíquico da } \\
\text { categoria bancária e evidenciam } \\
\text { que, fatores como a percepção da } \\
\text { interferência negativa do trabalho } \\
\text { em outras áreas da vida (RP= } \\
4,47) \text {, a exposição a conflitos } \\
(\mathrm{RP}=1,61) \text {, a existência de } \\
\text { individualismo e disputas } \\
\text { profissionais no ambiente de } \\
\text { trabalho (RP= 1,86), estão } \\
\text { intimamente relacionadas ao } \\
\text { sofrimento, sendo fatores } \\
\text { associados aos TMC. }\end{array}$ \\
\hline 7 & $\begin{array}{l}\text { Kayo Henrique Jardel } \\
\text { Feitosa Sousa } \\
\text { Danilo de Paiva Lopes } \\
\text { Gisele Massante Peixoto } \\
\text { Tracera } \\
\text { Ângela Maria Mendes Abreu }\end{array}$ & $\begin{array}{l}\text { Transtornos mentais } \\
\text { comuns entre } \\
\text { trabalhadores de } \\
\text { enfermagem de um } \\
\text { hospital psiquiátrico }\end{array}$ & 2019 & $\begin{array}{l}\text { Os achados das associações } \\
\text { permitem inferir que existe uma } \\
\text { relação entre os hábitos de vida } \\
\text { do trabalhador, sua atividade } \\
\text { laborativa e o } \\
\text { evidenciado desfecho } \\
\text { pelor maior }\end{array}$ \\
\hline
\end{tabular}




\begin{tabular}{|c|c|c|c|c|}
\hline & $\begin{array}{l}\text { Luciana Fernandes Portela } \\
\text { Regina Célia Gollner } \\
\text { Zeitoune }\end{array}$ & & & $\begin{array}{l}\text { percentual de transtornos mentais } \\
\text { comuns. Este estudo contribui } \\
\text { com subsídios para propostas de } \\
\text { intervenções e ações preventivas } \\
\text { para o adoecimento. }\end{array}$ \\
\hline 8 & $\begin{array}{l}\text { Danielle Machado Oliveira } \\
\text { Nicole Maria Brandim de } \\
\text { Mesquita Alencar } \\
\text { Jéssica Pereira Costa } \\
\text { Márcia Astrês Fernandes } \\
\text { Márcia Teles de Oliveira } \\
\text { Gouveia } \\
\text { José Diego Marques Santos }\end{array}$ & $\begin{array}{l}\text { Afastamento do } \\
\text { trabalho por } \\
\text { transtornos mentais e } \\
\text { comportamentais } \\
\text { entre } \\
\text { profissionais de } \\
\text { enfermagem }\end{array}$ & 2019 & $\begin{array}{l}\text { Estratégias de promoção da } \\
\text { saúde, reorganização das } \\
\text { condições de trabalho adequada } \\
\text { atenção à saúde mental desses } \\
\text { trabalhadores constituem-se em } \\
\text { importantes medidas para a } \\
\text { redução dos afastamentos do } \\
\text { trabalho. }\end{array}$ \\
\hline 9 & $\begin{array}{l}\text { Márcia Astrês Fernandes } \\
\text { Dinara Raquel Araújo Silva } \\
\text { Aline Raquel de Sousa } \\
\text { Ibiapina } \\
\text { Joyce Soares e Silva }\end{array}$ & $\begin{array}{l}\text { Adoecimento mental } \\
\text { e as relações com } \\
\text { o trabalho: estudo } \\
\text { com trabalhadores } \\
\text { portadores de } \\
\text { transtorno mental }\end{array}$ & 2018 & $\begin{array}{l}\text { Os trabalhadores percebem o } \\
\text { trabalho como um fator } \\
\text { influenciador para o seu } \\
\text { adoecimento mental, na medida } \\
\text { em que pode afetar suas relações } \\
\text { interpessoais, ser fonte geradora } \\
\text { de estresse e distúrbios no sono, } \\
\text { corroborando a literatura vigente, } \\
\text { nacional e internacional, acerca } \\
\text { do adoecimento mental e a } \\
\text { relação com o trabalho. }\end{array}$ \\
\hline 10 & $\begin{array}{l}\text { Daniela Zanoni Moreira } \\
\text { Maria Beatriz Rodrigues }\end{array}$ & $\begin{array}{l}\text { Saúde mental e } \\
\text { trabalho docente }\end{array}$ & 2018 & $\begin{array}{l}\text { A investigação dos afastamentos } \\
\text { por doença pode auxiliar na } \\
\text { identificação de riscos e na } \\
\text { promoção de um ambiente de } \\
\text { trabalho mais saudável e seguro } \\
\text { para os professores. }\end{array}$ \\
\hline 11 & $\begin{array}{l}\text { Márcia Astrês Fernandes } \\
\text { Géssica Spindola Castelo } \\
\text { Branco } \\
\text { Adriana Silveira Costa } \\
\text { Joyce Soares e Silva } \\
\text { Carla Danielle Araújo } \\
\text { Feitosa }\end{array}$ & $\begin{array}{l}\text { A relação saúde } \\
\text { mental e trabalho: } \\
\text { estudo em um } \\
\text { ambulatório } \\
\text { integrado de saúde } \\
\text { mental }\end{array}$ & 2017 & $\begin{array}{l}\text { O trabalho ao tempo em que pode } \\
\text { gerar danos a nível psíquico pode } \\
\text { também constituir-se em gerador } \\
\text { de experiências positivas e } \\
\text { reabilitadoras, no sentido em que } \\
\text { potencializa e dignifica o homem. }\end{array}$ \\
\hline 12 & $\begin{array}{l}\text { Liciane Diehl } \\
\text { Angela Helena Marin }\end{array}$ & $\begin{array}{l}\text { Adoecimento mental } \\
\text { em professores } \\
\text { brasileiros: revisão } \\
\text { sistemática da } \\
\text { literatura }\end{array}$ & 2016 & $\begin{array}{l}\text { Espera-se que esses resultados } \\
\text { direcionem novas pesquisas e } \\
\text { estimulem o planejamento de } \\
\text { intervenções eficazes voltadas } \\
\text { para a saúde mental de } \\
\text { professores. }\end{array}$ \\
\hline 13 & $\begin{array}{l}\text { João Silvestre Silva-JuniorI } \\
\text { Frida Marina Fischer }\end{array}$ & $\begin{array}{l}\text { Afastamento do } \\
\text { trabalho por } \\
\text { ranstornos mentais e } \\
\text { estressores } \\
\text { psicossociais } \\
\text { ocupacionais }\end{array}$ & 2015 & $\begin{array}{l}\text { A exposição ocupacional a } \\
\text { estressores psicossociais esteve } \\
\text { presente no relato da maioria dos } \\
\text { trabalhadores afastados do } \\
\text { trabalho por transtornos mentais. }\end{array}$ \\
\hline 14 & $\begin{array}{l}\text { Daniela Ornellas Ariño } \\
\text { Marúcia Patta Bardagi }\end{array}$ & $\begin{array}{l}\text { Relação entre Fatores } \\
\text { Acadêmicos e a } \\
\text { Saúde Mental de } \\
\text { Estudantes } \\
\text { Universitários }\end{array}$ & 2018 & $\begin{array}{l}\text { Dada a relação entre adoecimento } \\
\mathrm{e} \text { fatores acadêmicos e de } \\
\text { carreira, é necessário estabelecer } \\
\text { instrumentos para a detecção } \\
\text { precoce de sintomas de }\end{array}$ \\
\hline
\end{tabular}




\begin{tabular}{|c|c|c|c|c|}
\hline & & & & $\begin{array}{l}\text { transtornos mentais nesta } \\
\text { população, assim como ações que } \\
\text { favoreçam experiências } \\
\text { acadêmicas mais positivas. }\end{array}$ \\
\hline 15 & $\begin{array}{l}\text { Márcia Astrês Fernandes } \\
\text { Dinara Raquel Araújo Silva } \\
\text { Aline Raquel de Sousa } \\
\text { Ibiapina } \\
\text { Joyce Soares e Silva }\end{array}$ & $\begin{array}{l}\text { Adoecimento mental } \\
\text { e as relações com } \\
\text { o trabalho: estudo } \\
\text { com trabalhadores } \\
\text { portadores de } \\
\text { transtorno mental }\end{array}$ & 2018 & $\begin{array}{l}\text { Os trabalhadores percebem o } \\
\text { trabalho como um fator } \\
\text { influenciador para o seu } \\
\text { adoecimento mental, na medida } \\
\text { em que pode afetar suas relações } \\
\text { interpessoais, ser fonte geradora } \\
\text { de estresse e distúrbios no sono, } \\
\text { corroborando a literatura vigente, } \\
\text { nacional e internacional, acerca } \\
\text { do adoecimento mental e a } \\
\text { relação com o trabalho. }\end{array}$ \\
\hline 16 & $\begin{array}{l}\text { Vitória Nassar Viapiana } \\
\text { Rogério Miranda Gomes } \\
\text { Guilherme Souza Cavalcanti } \\
\text { de Albuquerque }\end{array}$ & $\begin{array}{c}\text { Adoecimento } \\
\text { psíquico na sociedade } \\
\text { contemporânea: notas } \\
\text { conceituais da teoria } \\
\text { da determinação } \\
\text { social do processo } \\
\text { saúde-doença }\end{array}$ & 2018 & $\begin{array}{l}\text { O desgaste gerado nesse processo } \\
\text { produz um perfil epidemiológico } \\
\text { marcado pelas altas taxas de } \\
\text { transtornos mentais. }\end{array}$ \\
\hline
\end{tabular}

Fonte: BVS, PubMed e ScienceDirect, 2020.

O corpo textual foi analisado por meio da frequência de palavras, que originou a nuvem de palavras (Figura 1) criada na Plataforma online WordArt. Esta ferramenta agrupa e organiza graficamente as palavras-chave, evidenciando as mais frequentes.

Figura 1. Nuvem de palavras elaborada na plataforma on-line do WordArt com base nas conclusões dos 16 artigos selecionados para discussão da temática principal do presente trabalho.

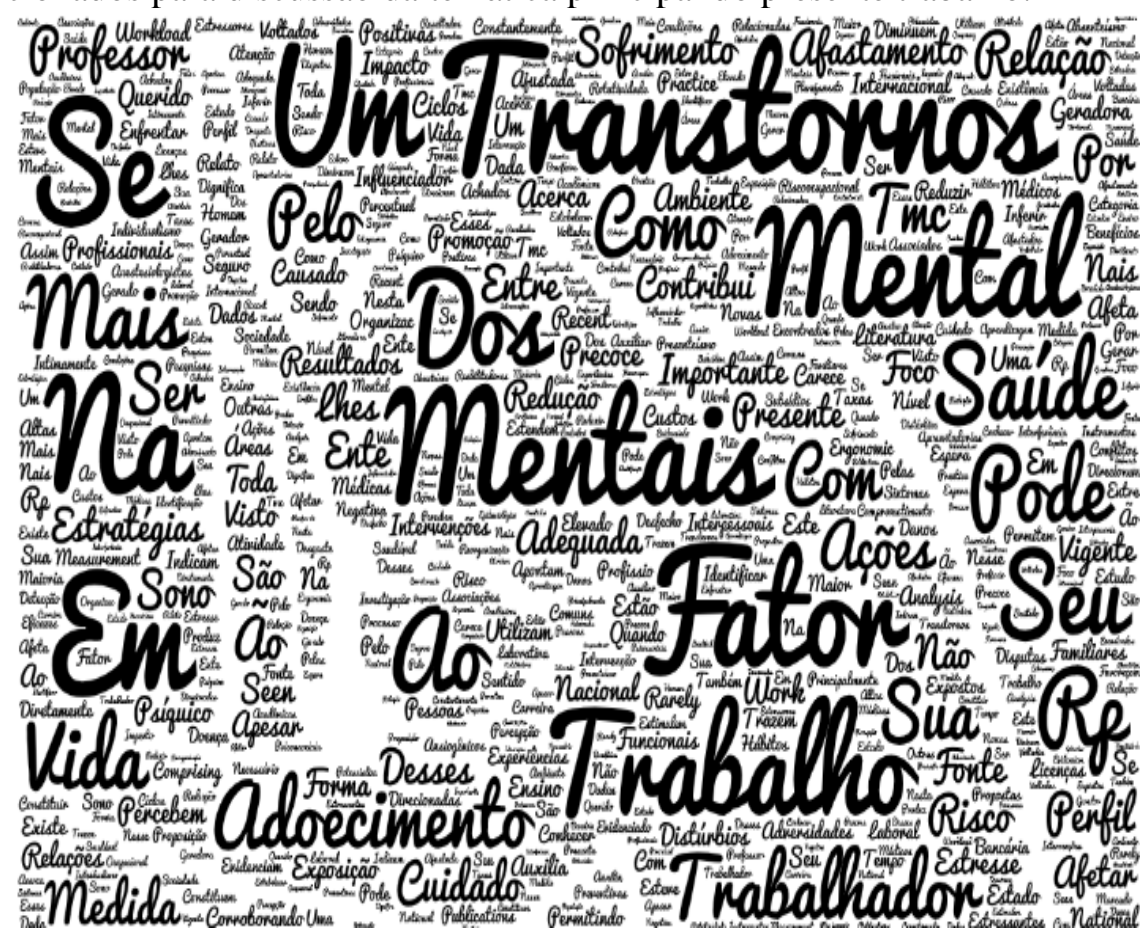


Fonte: autora.

Por meio da Figura 1, foi possível observar que as palavras em evidência na nuvem pertencem às categorias desenvolvidas a partir da análise de conteúdo de Bardin. Todas as categorias derivam da sua frequência (Tabela 1), que diz respeito ao seu quadro referencial. Em consonância ao objetivo deste trabalho, optou-se por descrever as palavras que apresentaram frequência total no texto e, a partir de seus sentidos nos campos textuais, tinham maior relevância para as representações sociais sobre o adoecimento e transtornos mentais, como apresentado na Figura1.

Tabela 1. Frequência das palavras presentes nos textos publicados nos sites BVS ScienceDirect.

\begin{tabular}{l|c|l}
\hline \multicolumn{1}{c|}{ PALAVRAS } & FREQUÊNCIA & \multicolumn{1}{c}{ CATEGORIAS } \\
\hline Adoecimento/Mental & $4 / 3$ & Adoecimento Mental dos Mestres \\
\hline Transtornos/ Mental & $3 / 3$ & Fatores Desencadeadores dos Transtornos Mentais \\
\hline Trabalho/Transtornos & $4 / 3$ & Transtornos Mentais no Trabalho \\
\hline
\end{tabular}

Fonte: autora.

\section{DISCUSSÃO}

O adoecimento e transtornos mentais precisam de ações positivas, para fins de facilitar as condições de uma vida com mais qualidade, tanto no pessoal quanto no profissional. Muitas dessas dificuldades vivenciadas no seu dia-a-dia, resultando no adoecimento e nos transtornos mentais (CORTEZ et al., 2017). Pode-se observar que essas mudanças só podem acontecer se mudar de forma geral as condições de trabalho desses profissionais. (MARANGONI et al.,2016).
Seguem abaixo, as categorias temáticas elaboradas a partir da revisão sistemática.

\section{Adoecimento Mental dos Professores}

Comumente, um transtorno de saúde mental ocorre em uma pessoa cuja composição genética a torna vulnerável. Essa vulnerabilidade, juntamente com os estresses da vida, por exemplo, problemas com a família ou trabalho, podem dar origem ao desenvolvimento de um transtorno mental (MOSCHEN PORT e AMAZARRAY, 2019).

Recentemente, considera-se que a doença mental é causada por uma interação 
complexa de fatores, incluindo fatores como: hereditários, biológicos, psicológico, ambientais, sociais e culturais. Fatores hereditários desempenham um papel fundamental em muitos transtornos de saúde mental. A cada passo, um transtorno de saúde mental ocorre em uma pessoa cuja composição genética a torna vulnerável a esses transtornos. Essa vulnerabilidade, juntamente com os estresses da vida, por exemplo, problemas com a família ou trabalho, podem dar origem ao desenvolvimento de um transtorno mental (MOREIRA e RODRIGUES, 2018).

Além disso, muitos especialistas acreditam que uma disfunção no controle dos mensageiros químicos no cérebro pode contribuir para os transtornos de saúde mental. Por isso, muitos transtornos de saúde mental parecem ter um componente biológico, muito parecidos com transtornos que são considerados neurológicos. No entanto, ainda não está claro se as alterações observadas nos exames de imagem são a causa ou o resultado do transtorno de saúde mental (MACHADO e LIMONGI, 2019).

Interações entre uma pessoa com doença mental grave e membros da família podem melhorar ou piorar a doença mental. Nesse sentido, desenvolveram-se técnicas de terapia familiar que evitam a necessidade de readmitir pessoas com doenças mentais crônicas em instituições de saúde mental. Atualmente, a família de uma pessoa com uma doença mental envolve-se mais do que nunca no tratamento, como uma aliada. O clínico geral também desempenha um papel importante na reintegração da pessoa com doença mental na sociedade (MACHADO, et al. 2019).

\section{Fatores Desencadeadores dos Transtornos Mentais}

Transtornos mentais são disfunções no funcionamento da mente, que podem afetar qualquer pessoa e em qualquer idade e, geralmente, são provocados por complexas alterações do sistema nervoso central. Existem diversos transtornos mentais, com apresentações diferentes. Eles geralmente são caracterizados por uma combinação de pensamentos, percepções, emoções e comportamento anormais, que também podem afetar as relações com outras pessoas (GRUGINSKI, GONTIJO e MERINO, 2015).

Entre os transtornos mentais, estão à depressão, o transtorno afetivo bipolar, a esquizofrenia e outras psicoses, demência, deficiência intelectual e transtornos de desenvolvimento, incluindo o autismo. Existem estratégias eficazes para a prevenção de transtornos mentais como a depressão (FERNANDES, et al. 2017). Há tratamentos eficazes para os transtornos mentais e maneiras de aliviar o sofrimento 
causado por eles. $\mathrm{O}$ acesso aos cuidados de saúde e aos serviços sociais capazes de proporcionar tratamento e apoio social é fundamental. A carga dos transtornos mentais continua crescendo, com impactos significativos sobre a saúde e as principais consequências sociais, de direitos humanos e econômicas em todos os países do mundo (FERNANDES, et al. 2018).

A depressão é um transtorno mental comum e uma das principais causas de incapacidade em todo o mundo. Globalmente, estima-se que 300 milhões de pessoas são afetadas por essa condição. Mais mulheres sofrem de depressão que homens. A depressão é caracterizada por tristeza, perda de interesse ou prazer, sentimento de culpa ou baixa autoestima, sono e apetite alterados, cansaço e falta de concentração (FAVATTO e BOTH, 2019). Quem sofre com essa condição pode também ter múltiplas queixas físicas sem nenhuma causa aparente. A depressão pode ser de longa duração ou recorrente, prejudicando substancialmente a capacidade das pessoas de serem funcionais no trabalho ou na escola, assim como a capacidade de lidar com a vida diária. Em seu estado mais grave, a depressão pode levar ao suicídio (DIEHL e MARIN, 2016).

Esse transtorno afeta milhões de pessoas em todo o mundo. Consiste tipicamente em episódios de mania e depressão, separados por períodos de humor normal. Os episódios de mania envolvem humor elevado ou irritado, excesso de atividade, pressão de fala, autoestima inflada e uma menor necessidade de sono. As pessoas que têm episódios de mania, mas não experimentam episódios depressivos, também são classificadas como tendo transtorno bipolar (CARDOSO, et al. 2015). Estão disponíveis abordagens eficazes para o tratamento da fase aguda do transtorno bipolar e para a prevenção de novas crises. Trata-se de medicamentos que estabilizam o humor. $\mathrm{O}$ apoio psicossocial é um componente importante na linha de tratamento (BIROLIM, et al. 2019).

A esquizofrenia é um transtorno mental grave que afeta cerca de 23 milhões de pessoas em todo o mundo. Psicoses, incluindo a esquizofrenia, são caracterizadas por distorções no pensamento, percepção, emoções, linguagem, consciência do “eu” e comportamento (ARIÑO e BARDAGI, 2018). As experiências psicóticas comuns incluem alucinações (ouvir, ver ou sentir coisas que não existem) e delírios (falsas crenças ou suspeitas firmemente mantidas mesmo quando há provas que mostram o contrário). $\mathrm{O}$ transtorno pode tornar difícil para as pessoas afetadas trabalhar ou estudar normalmente. $\mathrm{O}$ estigma e a 
discriminação podem diminuir o acesso à saúde e aos serviços sociais. Além disso, as pessoas com psicose correm alto risco de exposição a violações de direitos humanos, como o confinamento de longo prazo em instituições (ARIÑO e BARDAGI, 2018).

A esquizofrenia geralmente tem início ao fim da adolescência ou no começo da vida adulta. $\mathrm{O}$ tratamento com medicamentos e apoio psicossocial é eficaz. Com o tratamento adequado e suporte social, as pessoas afetadas podem voltar a ter uma vida produtiva e integrada à sociedade (ARIÑO e BARDAGI, 2018). Ampliar o acesso a formas de assistência cotidiana, atenção domiciliar e suporte para a inserção no mercado de trabalho são medidas de apoio para que as pessoas que sofrem com transtornos mentais graves, como a esquizofrenia, atinjam os objetivos de sua reabilitação, já que enfrentam maiores dificuldades em acessar empregos ou residência (ANDRADE e ANDRADE DANTAS, 2015).

Em todo o mundo, cerca de 50 milhões de pessoas têm demência. A condição é geralmente de natureza crônica ou progressiva, na qual há deterioração da função cognitiva (isto é, a capacidade de processar o pensamento) para além do que se poderia esperar no envelhecimento normal. Ela afeta memória, pensamento, orientação, compreensão, cálculo, capacidade de aprendizagem, linguagem e julgamento. O comprometimento da função cognitiva é comumente acompanhado, e ocasionalmente precedido, pela deterioração do controle emocional, comportamento social ou motivação (POMPEO, et al. 2016).

O termo transtorno de desenvolvimento abrange deficiência intelectual e transtornos invasivos de desenvolvimento, incluindo o autismo. Os distúrbios de desenvolvimento geralmente têm início na infância, mas tendem a persistir na idade adulta, causando comprometimento ou atraso nas funções relacionadas à maturação do sistema nervoso central (POMPEO, et al. 2016). Eles geralmente seguem um curso constante, em vez de os períodos de alternância entre estabilizações e crises que caracterizam muitos outros transtornos mentais. A deficiência intelectual é caracterizada pela diminuição de habilidades em várias áreas de desenvolvimento, como o funcionamento cognitivo e o comportamento adaptativo. Essa condição diminui a capacidade de adaptação às exigências diárias da vida (RIBEIRO, et al. 2019).

Os sintomas de transtornos invasivos de desenvolvimento, como o autismo, são comportamento social, comunicação e linguagem prejudicados e 
uma estreita faixa de interesses e atividades, que são únicas para o indivíduo e realizadas repetidamente (SILVA, 2015). Os transtornos de desenvolvimento frequentemente se originam na infância ou na primeira infância. As pessoas com esses transtornos ocasionalmente possuem algum grau de deficiência intelectual. O envolvimento da família no cuidado de pessoas com essa condição é fundamental. É importante conhecer as situações e atividades que causam tensão e bem-estar ao indivíduo, assim como descobrir quais ambientes são mais apropriados para uma melhor aprendizagem (SILVA e CARVALHO E, 2016). O estabelecimento de rotinas diárias (horários para alimentação, brincadeiras, contato com outras pessoas e sono) ajuda a prevenir estresse desnecessário. É essencial também que os serviços de saúde façam um acompanhamento regular de crianças e adultos com transtornos de desenvolvimento e se mantenham em contato com seus cuidadores (SOUSA, et al. 2019).

Os determinantes da saúde mental e transtornos mentais incluem não apenas atributos individuais, como a capacidade de administrar os pensamentos, as emoções, os comportamentos e as interações com os outros, mas também os fatores sociais, culturais, econômicos, políticos e ambientais, como as políticas nacionais, a proteção social, padrões de vida, as condições de trabalho e o apoio comunitário (SILVA-JUNIOR e FISCHER, 2015). Os sistemas de saúde ainda não responderam adequadamente à carga dos transtornos mentais. Como consequência, a distância entre a necessidade de tratamento e sua oferta é ampla em todo o mundo. Além do apoio dos serviços de saúde, pessoas com transtornos mentais precisam de apoio e cuidados sociais. Frequentemente necessitam também de ajuda para acessar programas educativos que se adaptem às suas necessidades e encontrar emprego e moradia que lhes permitam viver e ser ativos nas suas comunidades locais (SOUZA, et al. 2017).

\section{Transtornos Mentais no Trabalho}

Transtornos mentais relacionados ao trabalho são comuns nos dias de hoje, e isso já faz também um bom tempo, pois existem vastos resultados e situações de processo de trabalho, provenientes de fatores pontuais como exposição a determinados agentes tóxicos, até a completa articulação de fatores relativos à organização do trabalho, como a divisão e parcelamento das tarefas, as políticas de gerenciamento das pessoas no trabalho e a estrutura hierárquica organizacional, onde todos esses fatores levam a diversos transtornos mentais 
(MOSCHEN PORT e AMAZARRAY, 2019). Devendo-se observar que isso significa um agravo que está relacionado diretamente as suas condições de trabalho. Para formalizar a relação com o trabalho (VIAPIANA, GOMES e ALBUQUERQUE, 2018).

As diversas causas que levam aos transtornos mentais são fatores que muitas vezes não são levados em como: a falta de controle sob o ritmo de trabalho e cobrança por produção e realização de tarefas complexas, relacionamentos interpessoais ruins, tanto verticais (com os chefes), quanto horizontais (entre os próprios colegas), violência no trabalho com situações de humilhação, perseguição, agressões física e verbal, desequilíbrio entre esforço e recompensa, dedicação excessiva ao trabalho, exposição a produtos químicos como metais pesados e solventes: brometo de metila; chumbo ou seus compostos tóxicos; manganês e seus compostos tóxicos; mercúrio e seus compostos tóxicos; sulfeto de carbono; tolueno e outros

\section{CONCLUSÃO}

A avaliação sobre o adoecimento e transtornos mentais decorrentes de condições adversas do professor, a partir das experiências e saberes, permitiu revelar uma série de elementos para a compreensão não apenas do processo de retorno ao solventes aromáticos neurotóxicos; tricloroetileno, tetracloroetileno, tricloroetano e outros solventes orgânicos halogenados neurotóxicos; outros solventes orgânicos neurotóxicos, estresse no trabalho decorrente da pressão por cumprir prazos e metas, competitividade, organização do trabalho: a forma como se ordenam as tarefas necessárias aos objetivos do empregador. Implica a coordenação das tarefas, a divisão do trabalho, a organização temporal das atividades como ritmo, pausas, trabalho em turno, equipes, premiação, controle do trabalho, estabelecimento de metas, etc. (ANDRADE e ANDRADE DANTAS, 2015).

$\mathrm{Na}$ verdade, tem-se uma lista interminável de fatores que afetam diretamente o trabalho desses profissionais se não forem vista com um olhas mais qualificado, para que assim possasse ter uma melhor qualidade de vida profissional e social (MACHADO, et al. 2019).

adoecimento e transtornos, como sobre os afastamentos e as condições de vida e trabalho nesta categoria profissional.

Compreendeu-se que, é necessário examinar a rede de causas relacionadas a esses transtornos e adoecimentos. Tal assertiva, embora pareça óbvia, repousa 
justamente no pressuposto de que os trabalhadores e os professores deste estudo retornam ao trabalho em condições semelhantes àquelas que influenciaram o adoecimento e os transtornos. Se fossem tomadas medidas de melhorias das condições e organização de trabalho na escola, como, por exemplo, em relação aos aspectos psicossociais, estas beneficiariam toda a comunidade escolar, não apenas os professores ativos.

Os sentidos atribuídos para o adoecimento indicaram que a maioria dos professores trabalham em condições não desejadas e desfavoráveis à saúde. Para os

\section{REFERÊNCIAS}

ANDRADE, G. O.; ANDRADE

DANTAS, R. A. Transtornos mentais e do comportamento relacionados ao trabalho em médicos anestesiologistas. Brazilian Journal of Anesthesiology, 2015. v. 65, n. 6, p. 504-510.

ARAÚJO, T. M.; PALMA, T. D. F.; ARAÚJO, N. D. C. Work-related mental health surveillance in Brazil:

Characteristics, difficulties, and challenges. Ciência e Saúde Coletiva, v. 22, n. 10, p. 3235-3246, 2017.

ARIÑO, D. O.; BARDAGI, M. P. Relação entre Fatores Acadêmicos e a Saúde Mental de Estudantes Universitários. Revista Psicologia em Pesquisa, 2018. v. 12, n. 3, p. 44-52.

BIROLIM, M. M. et al. Job strain among teachers: Associations with occupational factors according to social support. professores às condições de satisfação profissional, saúde e efetividade do processo são essenciais para um bom desenvolvimento do seu trabalho.

Por fim, os resultados deste estudo revelaram que, para estes professores, o processo de adoecimento e transtornos mentais depende de vários fatores para que haja uma progressão futura. Apoiando-se em um o conhecimento dos processos que determine os níveis singular, particular e geral, assim como das relações que se formam entre os níveis, o que escapa da abrangência deste trabalho.

Ciência e Saúde Coletiva, v. 24, n. 4, p. 1255-1264, 2019.

CARDOSO, M. C. A. et al. Saúde do trabalhador no processo de negociação coletiva no Brasil. São Paulo:

Departamento Intersindical de Estatística e Estudos Socioeconômicos. v. 76, 2015.

CORTEZ, P. A. et al. A saúde docente no trabalho: apontamentos a partir da literatura recente. Cadernos de Saúde Coletiva [on-line], Rio de Janeiro, v. 25, n. 1, p. 113-122, 2017.

DIEHL, L.; MARIN, A. H. Adoecimento mental em professores brasileiros: revisão sistemática da literatura. Estudos

Interdisciplinares em Psicologia, 2016. v. 7, n. 2, p. 64.

FAVATTO, N. C.; BOTH, J. Reasons for abandonment and staying in the teaching career in physical education. Revista 
Brasileira de Ciências do Esporte, v. 41, n. 2, p. 127-134, 2019.

FERNANDES, M. A. et al. Mental illness and its relationship with work: A study of workers with mental disorders. Revista Brasileira de Medicina do Trabalho, 2018. v. 16, n. 3, p. 277-286.

FERNANDES, M. A. et al. The relationship between mental health and work: integrated mental health outpatient center study. Revista de Enfermagem UFPE on Line, 2017. v. 11, n. 10, p. 4191-4198.

GRUGINSKI, B. E.; GONTIJO, L. A.; MERINO, E. Frequency of Application of Mental Workload Measuring Instruments in Recent Publications in Brazil. Procedia Manufacturing, 2015. v. 3, n. Ahfe, p. 5134-5138.

MACHADO O. D. et al. Afastamento do trabalho por transtornos mentais e comportamentais entre profissionais de enfermagem. Revista Cuidarte, 2019. v. 10, n. 2, p. 1-11.

MACHADO, L. C.; LIMONGI, J. E. Prevalence and factors associated to common mental disorders among municipal teachers in Uberlândia, Minas Gerais, Brazil. Revista Brasileira de Medicina do Trabalho, 2019. v. 17, n. 3, p. 325-334.

MARANGONI, V. S. L. et al. Afastamento laboral por transtornos mentais entre os servidores da prefeitura municipal de Manaus: uma análise preliminar. Semina: Ciências Biológicas e da Saúde, v. 37, n. 2, p. 13, 2016.

MOREIRA, D. Z.; RODRIGUES, M. B. Mental health and teaching. Estudos de Psicologia, 2018. v. 23, n. 3, p. 236-247.

MOSCHEN PORT, R.; AMAZARRAY, M. R. Transtornos mentais comuns e fatores associados em trabalhadores bancários do Rio Grande do Sul, Brasil.

Revista Psicologia: Organizações e Trabalho, 2019. v. 19, n. 1, p. 515-522.

POMPEO, D. A. et al. Estratégias de enfrentamento de familiares de pacientes com transtornos mentais. Revista LatinoAmericana de Enfermagem, 2016. v. 24.

RIBEIRO, H. K. P. et al. Transtornos de ansiedade como causa de afastamentos laborais. Revista Brasileira de Saúde Ocupacional, 2019. v. 44, p. 1-8.

SILVA, E. P. Adoecimento e sofrimento de professores universitários: dimensões afetivas e ético-políticas. Psicologia: teoria e prática. 2015. doi: 10.15348/1980-6906.

SILVA, E. S. Desemprego e desgaste mental: desafio as políticas públicas e aos sindicatos. Ciências do Trabalho, São Paulo, n. 4, p. 89-109, 2015.

SILVA, T. R.; CARVALHO E. A. Depressão em professores universitários: uma revisão da literatura brasileira. 2016.

SILVA-JUNIOR, J. S.; FISCHER, F. M. Afastamento do trabalho por transtornos mentais e estressores psicossociais ocupacionais. Revista Brasileira de Epidemiologia, 2015. v. 18, n. 4, p. 735744.

SOUSA, K. H. J. F. et al. Transtornos mentais comuns entre trabalhadores de enfermagem de um hospital psiquiátrico. Acta Paulista de Enfermagem, 2019. v. 32, n. 1, p. 1-10.

SOUZA, K. R. et al. A nova organização do trabalho na universidade pública: Consequências coletivas da precarização na saúde dos docentes. Ciência e Saúde Coletiva. v. 22, n. 11, p. 3667-3676, 2017. 
VIAPIANA, V. N.; GOMES, R. M.; ALBUQUERQUE, G. S. C. De.

Adoecimento psíquico na sociedade contemporânea: notas conceituais da teoria da determinação social do processo saúdedoença. Saúde em Debate, 2018. v. 42, n. spe4, p. 175-186. 